\title{
Case Report: Literature review of a Complicated Postpartum
}

\section{Pubic Symphysitis case [version 1; peer review: 2 approved}

\section{with reservations]}

\author{
Dhekra Toumi1 ${ }^{1}$ Korbi Asma (D1), Marwa Badr1', Farouk Ennaceur(D1, \\ Boujemaa Touati², Ahmed Hajji1, Raja Faleh¹
}

${ }^{1}$ Department of Gynecology and Obstetrics, University Hospital Fattouma Bourguiba, Monastir, Monastir, 5000, Tunisia

${ }^{2}$ Department of Orthopedic, University Hospital Fattouma Bourguiba, Monastir, Monastir, 5000, Tunisia

V1 First published: 10 May 2021, 10:364
https://doi.org/10.12688/f1000research.52234.1

Latest published: 10 May 2021, 10:364

https://doi.org/10.12688/f1000research.52234.1

\begin{abstract}
Post-partum pubic symphysitis is an exceptional pathology. Its diagnosis is difficult, based on a high clinical semiological finesse complemented by imaging examinations, the most specific of which are CT and pelvic MRI. The earlier the diagnosis, the better the evolution. We report a case of pubic symphysitis occurring in the aftermath of a low-pathway delivery discovered in a septic shock table. Evolution was good under antibiotic and heparin therapy.
\end{abstract}

\section{Keywords}

Post-partum, pubic symphysitis, case report.

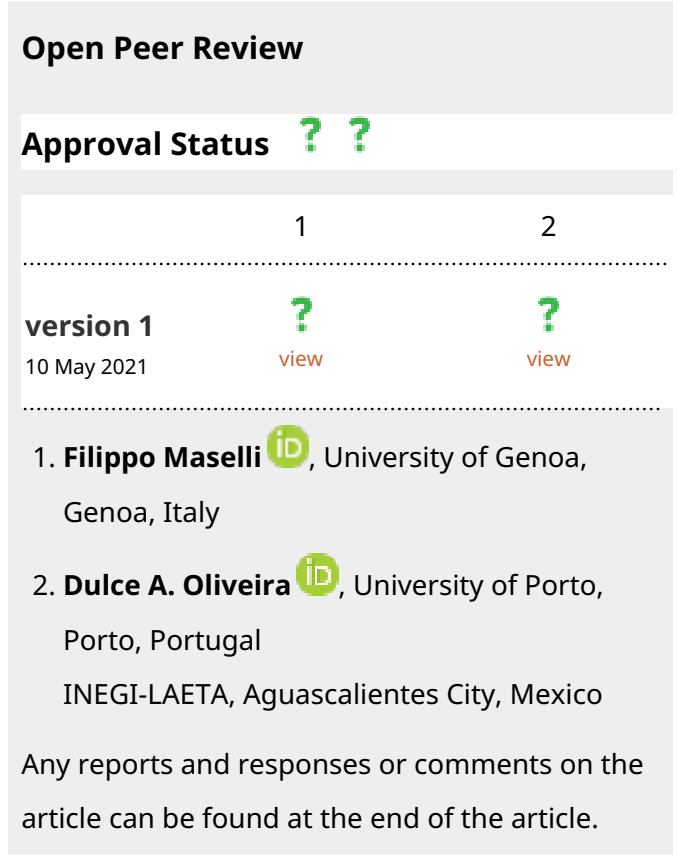

Corresponding author: Korbi Asma (korbi.asma@live.fr)

Author roles: Toumi D: Funding Acquisition, Investigation; Asma K: Visualization, Writing - Review \& Editing; Badr M: Resources, Software; Ennaceur F: Writing - Original Draft Preparation, Writing - Review \& Editing; Touati B: Conceptualization, Data Curation; Hajji A: Software; Faleh R: Supervision, Validation

Competing interests: No competing interests were disclosed.

Grant information: The author(s) declared that no grants were involved in supporting this work.

Copyright: @ 2021 Toumi D et al. This is an open access article distributed under the terms of the Creative Commons Attribution License, which permits unrestricted use, distribution, and reproduction in any medium, provided the original work is properly cited.

How to cite this article: Toumi D, Asma K, Badr M et al. Case Report: Literature review of a Complicated Postpartum Pubic Symphysitis case [version 1; peer review: 2 approved with reservations] F1000Research 2021, 10:364 https://doi.org/10.12688/f1000research.52234.1

First published: 10 May 2021, 10:364 https://doi.org/10.12688/f1000research.52234.1 


\section{Introduction}

Septic arthritis of the pubic symphysis is a rare infection, often occurring in particular patients including: athletes with chronic pubic inflammation, women in the postpartum period, drug addicts, patients following a surgical treatment for urinary incontinence or patients with pelvic cancer. ${ }^{1,2}$

To date, it is an often unknown infection because it is sometimes difficult to diagnose especially as the nosology remains unclear in the literature. Indeed, it must be suspected in the presence of pelvic girdle pain with fever and sometimes lameness or painful irradiation towards the lower limbs, but the symptomatology can be misleading. ${ }^{3}$

This clinical presentation helps guide additional studies that are not always specific with many differential diagnoses. CT and MRI are the two most sensitive exams. ${ }^{3,4}$

As for treatment, there are several therapeutic options whose pillar is antibiotic therapy. ${ }^{5,6}$

We present here a case of pubic symphysitis complicating the postpartum period.

\section{Case report}

This was a 31-year-old female Caucasian patient with no relevant personal or family history who was re-admitted at day 25 postpartum for septic shock. The patient was primigravid, with no significant pathological history.

The pregnancy was normal. The patient had a low-birth-weight newborn baby of $3750 \mathrm{~g}$. The delivery was without incident. The day after the delivery, the physical examination was strictly normal and the patient was discharged.

At day 15 postpartum, the patient described a gait lameness due to bilateral inguinal pain, in the context of unencrypted fever. The patient took this to be common postpartum joint pain and self-medicated with analgesics. However, the evolution was marked by the aggravation of functional impotence becoming disabling with the appearance of a fever which did not respond to medical treatment; thus, the patient consulted us.

Clinical examination at admission found a confused patient, febrile at $39^{\circ} \mathrm{C}$, heart rate of $160 \mathrm{bpm}$, with blood pressure at $80 / 60 \mathrm{mmHg}$, hypogastric defense and sensitivity to palpation of the pubic symphysis and hip mobilization. The diagnosis of septic shock was retained. After conditioning, a pelvic ultrasound was performed showing multiple hyperechogenic heterogeneous compartmentalized collections occupying almost the entire pelvis without visualization of the uterus or ovaries.

We then performed an abdomino-pelvic CT that showed multiple compartmentalized collections, communicating with peripheral enhancement and water contents, distributed in the form of cubicles of variable size and shape occupying almost the entire perineum (intra-muscular), fusing within the root muscles of the lower limbs, coxo-femoral joints, rectus muscles and along the iliacus and psoas muscles. Calcifications were found within these collections (osteolysis). The most voluminous cubicle was located opposite the the $15-\mathrm{mm}$ pubic symphysis. Osteolysis of the ilio- and ischiopubic branches responsible for total disjunction with pubic diastasis. Floating, marginal and total thrombus in places at the level of the iliac bifurcation, the left common and external iliac veins, the right external iliac vein and bilateral common femoral veins (Figure 1).

A few hours after admission, the patient's condition quickly deteriorated with a severe collapse and recourse to noradrenaline. After conditioning, a laparotomy was made with exploration resulting from the collection of two liters of frank pus from Retzius' space, with the presence of free bone fragments and a significant osteolysis of the pubic symphysis.

The initial investigations were bacteriological sampling, removal of the bone sequester with slight bone and excision of the false membranes, an access to the cubicles at the perineal muscles and iliopsosas and cleaning with physiological serum. Then we entered into exploration of the peritoneal cavity, which was without anomalies. At the end of the operation, two undulating blades were installed at the root of the lower limbs and a Salem probe between the bladder and the uterus (Figure 2).

Biologically there was moderate leukocytosis at 10,000 cells $/ \mathrm{mm}^{3}$, associated with an inflammatory syndrome $(\mathrm{CRP}=$ $30 \mathrm{mg} / \mathrm{L})$.

The diagnosis of septic arthritis of the complicated pubis of a state of septic shock with abscesses in adjacent muscles and extensive iliac venous thrombosis was therefore retained. The patient was placed on broad-spectrum probabilistic 

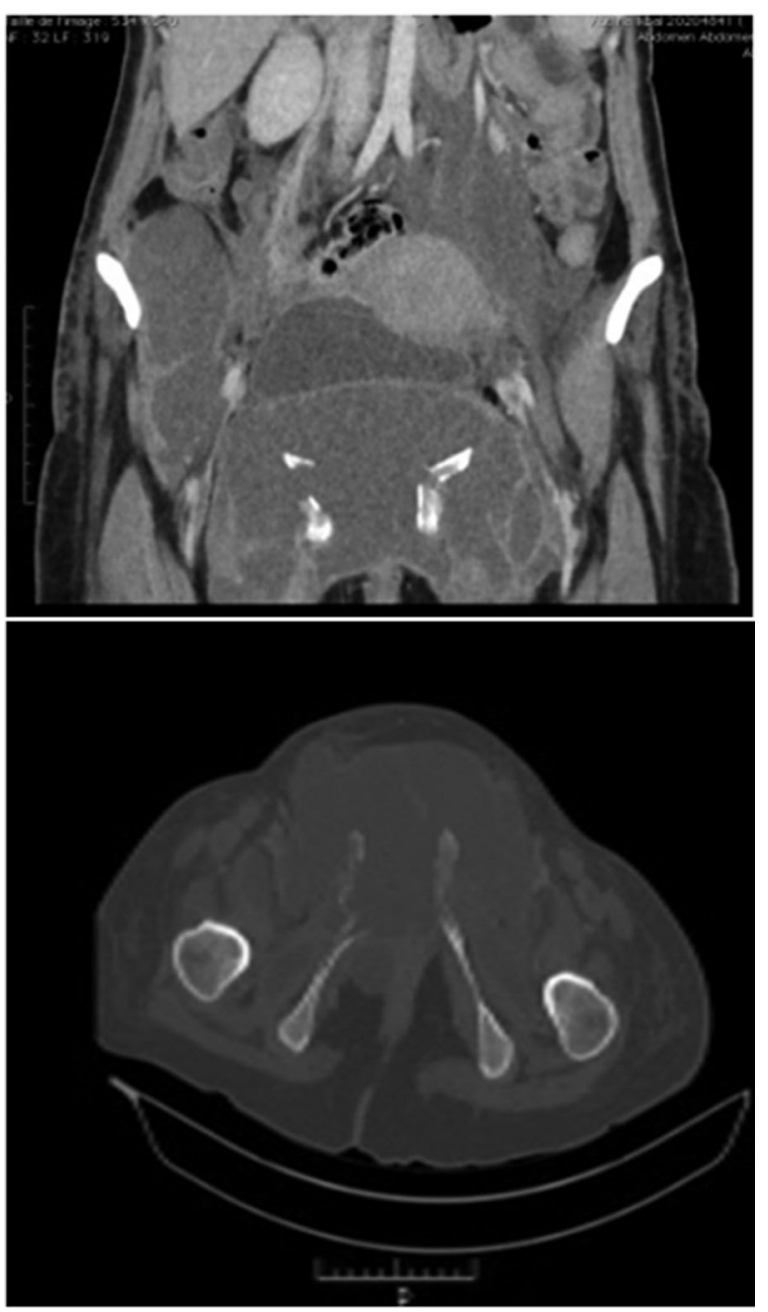

\section{Figure 1. CT aspect of the Pubic Symphysitis.}

antibiotic therapy using vancomycin (500 mg four times per day) and Tienam ( $1 \mathrm{~g}$ four times per day) parenteral antibiotics and on a curative dose low-molecular-weight heparin. The bacteriological sampling done per-operatively and the blood cultures came back negative. The evolution was marked by progressive clinical improvement.

A control CT was performed on day 13 of the treatment objectifying: 1) a right retroperitoneal collection of $5 \times 7 \mathrm{~cm} ; 2$ ) a partial regression of the collections of the left iliopsoas muscle; 3 ) a raised wall delimiting multiple communicating cubicles; 4) a near total regression of the perineal collections, the right abdominal muscle and the roots of the lower limbs; 5) a stable aspect of venous thrombosis; and 6) as well as bilateral anterior osteolysis of the ilio and ischio pubic branches. Following these CT findings, a CT-guided puncture was then used in the retroperitoneal collection bringing back a thick greenish liquid with the installation of a drain (Figure 3).

Dual therapy was maintained for 6 weeks with an apyrexia as of day 3. Biological inflammatory syndrome disappeared after one month. The removal of the two initially placed corrugated blades was done after 3 weeks.

The patient was asymptomatic during the last check-up with a recoil of 8 months.

\section{Discussion}

Pubic symphysis represents less than $1 \%$ of all hematogenous osteomyelitis. ${ }^{7}$ They are exceptional in post-partum women. ${ }^{6}$ This is the first case encountered in our service. Pubic symphysis often occurs in a particular field causing symphysis lesions or locoregional infection. ${ }^{3}$ 


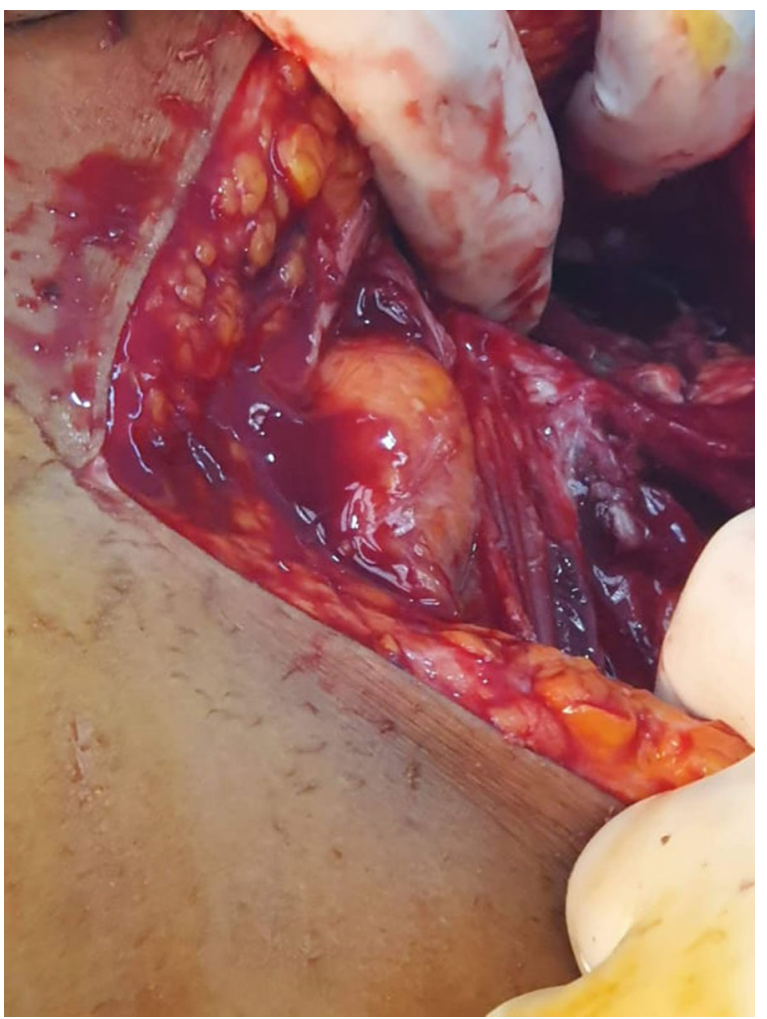

Figure 2. Pus and free bone fragments and osteolysis of the pubic symphysis.

Indeed, in post-partum women, in addition to the risk of lesions of the symphysis in peripartum (even in the absence of traumatic childbirth), the immunodeficiency due to pregnancy and delivery promotes the pillulation of germs. Concerning the pathophysiology, it is still poorly elucidated by Mynors in 1974 suggested that it is mainly pubic thrombosis due to the dramatic response to heparinization of resistant cases of pubic osteitis. ${ }^{8}$

The pubic symphysitis in post-partum is difficult and often late diagnosis because pain is often related to the circumstances of childbirth with recourse to self medication that will alleviate the symptomatology. According to a literature review of 100 cases of pubic symphysitis, published by Ross et al. ${ }^{6}$ In 2003, most patients reported pubic pain (68\%). Pain is also localized to the groin (41\%), thigh (15\%) and hip (12\%), probably due to radiation along the hip adductors, which insert onto the pubic symphysis.

Reaching the hip adductors also explains the pain during walking (59\%) and hip movement (45\%). Long delays between symptom onset and diagnosis were typical (mean, 29 days), due to insidious presentation and low clinical suspicion of this rare disease. ${ }^{6}$ In our patient the diagnosis was made 10 days after the onset of symptoms.

Indeed, the secondary appearance of a pain that did not exist in early post-partum, its increasing intensity, or its unfavourable and unconventional evolution, the presence of a fever or a functional impotence associated especially after non-dystocic delivery are elements that can guide the diagnosis. ${ }^{9}$

To support the diagnosis or guide the samples two essential examinations to be requested are CT and MRI of the pelvis.,

These examinations typically show bone erosions, a bank abscess, enlargement or effusion of the pubic symphysis. MRI provides early detection of edema and inflammation of the bone and muscles, intra-articular effusion or abscess. ${ }^{4}$

It will then be necessary to search for the responsible germ. Staphylococci aureus (34\%) and Pseudomonas aeruginosa (24\%) are the bacteria most often incriminated. ${ }^{3}$ Pubic symphysis with group B streptococcus are exceptional. ${ }^{6}$ This bacteria can be isolated in blood cultures or post-partum lochia. If this investigation is negative, a local biopsy sample by 

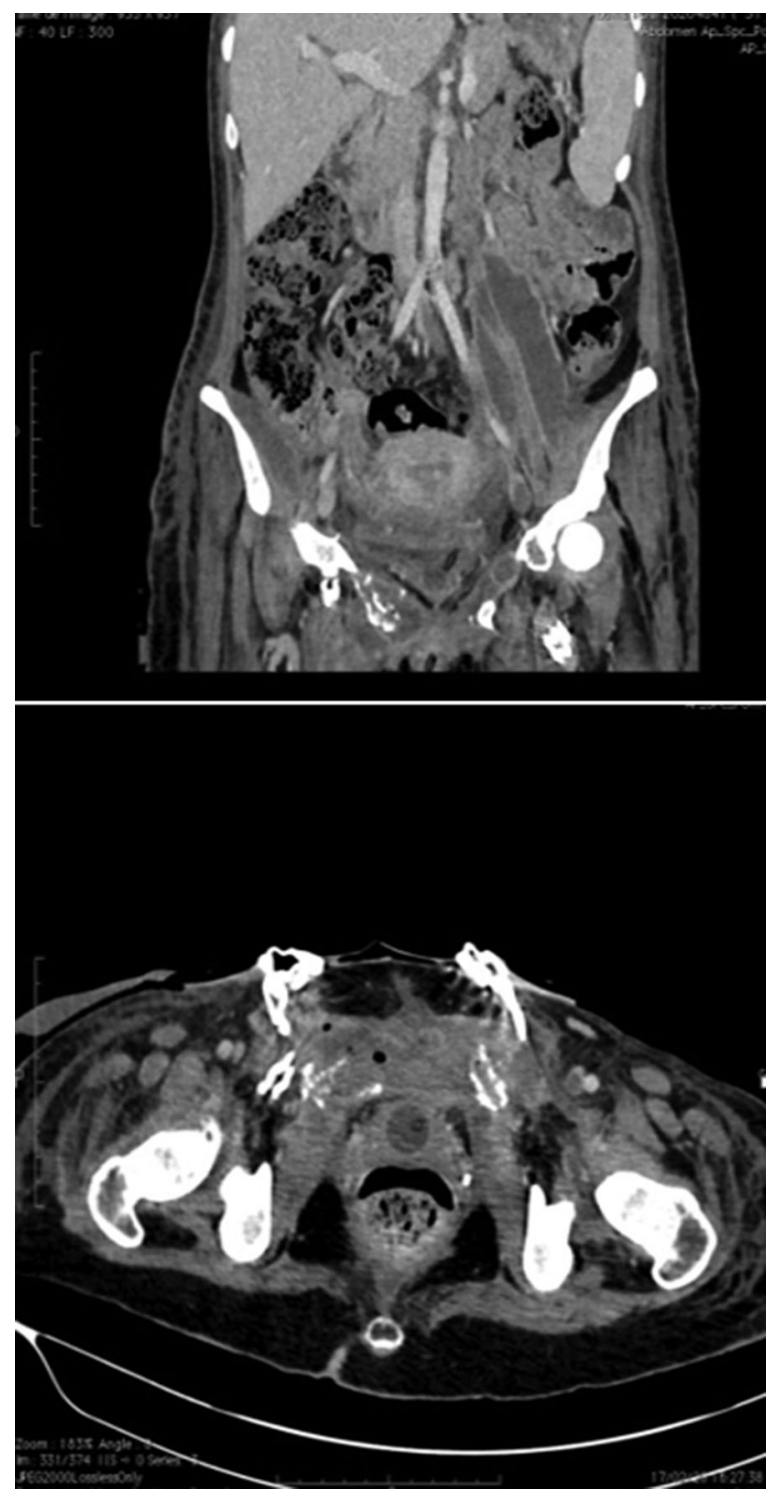

Figure 3. Control CT (Day 13).

trocar or surgical biopsy may be proposed. The low virulence of these bacteria, their long culture time, or prior antibiotic therapy may lead to the culture being wrongly considered sterile ${ }^{3}$ as is the case with our observation.

In this pathology, the biological signs are neither specific nor constant. In the majority of cases, there is an inflammatory syndrome with increased sedimentation rate, but leukocytosis is inconstant, exceeding 11000 cells per mm ${ }^{3}$ in only $35 \%$ of cases according to the same series. ${ }^{6}$ For our case, the inflammatory syndrome is moderate with leukocytosis at 10000 and CRP at 30 despite the severity of the clinical picture and per-operative findings.

The treatment is based, classically, on antibiotic therapy of at least 6 weeks sometimes associated with the drainage of a collection. ${ }^{6}$ But there is no clear recommendation in the literature about which molecule to use.

The evolution is generally favorable in case of early diagnosis and treatment; however, $55 \%$ of patients required surgery either for debridement or for abscess evacuation. ${ }^{10}$ In the absence of treatment, the progression can be towards chronicity with the possibility of appearance of fistulas, bone sequesters and the possibility of pelvic cellulitis. ${ }^{11}$

For our patient, although she presented with septic shock and the per-operative findings were serious, the evolution was still favorable. 
The control check is based mainly on the clinical evolution and the surveillance of the inflammatory syndrome because the imaging takes a long time to show a healing para port to the clinical cure. But for our patient, we asked early for a control scan of extensive associated lesions (venous thrombosis and abscess of the soft parts).

\section{Conclusion}

Post-partum pubic symphysitis is a very rare condition with a difficult diagnosis. Two essential tests that should not be delayed to confirm the diagnosis: CT and pelvic MRI are required to confirm the diagnosis and eliminate complications. A treatment based on antibiotic therapy is to start from the diagnosis because the earlier treatment, the more favorable the evolution.

\section{Data availability}

Underlying data

All data underlying the results are available as part of the article and no additional source data are required.

\section{Consent}

Written informed consent for publication of their clinical details and/or clinical images was obtained from the patient.

1. Charles $P$, et al.: Arthrites septiques spontanées à streptocoques de la symphyse pubienne. La Revue de médecine interne. 2011; 32(7): e88-e90.

Publisher Full Text

2. Rosenthal RE, Anderson Spickard W, Douglass Markham R, et al.: Osteomyelitis of the symphysis pubis: a separate disease from osteitis pubis. J Bone Joint Surg. 1982; 64: 123-8. PubMed Abstract

3. Salomon S, Lasselin-Boyard P, Lasselin J, et al.: Symphysite pubienne infectieuse post-chirurgicale. Progrès en urologie. 2015; 25(3): 169-74. Publisher Full Text

4. Jarlaud T, Railhac JJ, Sans N, et al.: Normal and patho-logic symphysis pubis: value of imaging. J Radiol. 2001; 82: 425-36. PubMed Abstract

5. Grace JN, Sim FH, Shives TC, et al.: Wedge resection of the symphysis pubis for the treatment of osteitis pubis. J Bone Joint Surg. 1989; 71: 3586-94.

PubMed Abstract
6. Ross J, Hu LT: Septic arthritis of the pubic symphysis: review of 100 cases. Medicine. 2003; 82(5): 340-5. PubMed Abstract | Publisher Full Text

7. Arlet J, Bouteiller G, Durroux R, et al.: Ostéites pubiennes et ischiopubiennes. Étude bactériologique et histopathologique de l'os pubien. Rev Rhum. 1981; 48: 101-6.

8. Mynors JM: Osteitis pubis. J Urol. 1974 Nov; 112(5): 664-5.

9. Kehila M, Majdoub M, Zegha D: La symphysite pubienne du postpartum: un diagnostic difficile. Pan Afr Med J. 2014, vol. 16, no 1. PubMed Abstract | Publisher Full Text | Publisher Full Text

10. Ducrotoy V, Fournet $P$, Vittecoq $O$, et al.: Postpartum septic arthritis - Two case reports. J Gynecol Obstet Biol Reprod (Paris). 1998 Jun; 27(4): 449-54. PubMed Abstract

11. Choi $\mathrm{H}, \mathrm{McC}$ artney $\mathrm{M}$, Best TM: Treatment of osteitis pubis and osteomyelitis of the pubic symphysis in athletes: a systematic review. Br J Sports Med. 2011 Jan; 45(1): 57-64. PubMed Abstract | Publisher Full Text | Publisher Full Text 


\section{Open Peer Review}

\section{Current Peer Review Status: ? ?}

\section{Version 1}

Reviewer Report 21 October 2021

https://doi.org/10.5256/f1000research.55480.r96788

(C) 2021 Oliveira D. This is an open access peer review report distributed under the terms of the Creative Commons Attribution License, which permits unrestricted use, distribution, and reproduction in any medium, provided the original work is properly cited.

\section{Dulce A. Oliveira \\ 1 University of Porto, Porto, Portugal \\ 2 INEGI-LAETA, Aguascalientes City, Mexico}

My area of expertise is biomedical engineering so reviewing this paper is quite difficult.

The authors show that it is a case that deserves to be studied because of its rareness, but the case they present should be explored more so that it can also be useful for other colleagues. One would expect more information about the patient, more detail about the choices made and why, alternatives that could have been pursued and justification for not doing so, etc.

The introduction is a bit poor, it would be interesting to present some numbers, for example, the percentage of women who suffer from this infection, the percentage of women who have their postpartum aggravated due to this condition, etc. The paragraph regarding treatments could also be further explored, even though the treatment mentioned was the one used in this case report.

In the introduction you refer to "Septic arthritis of the pubic symphysis". Does this correspond to pubic symphysitis?

What is the main goal of the study? Will the present study help on the early diagnosis of future pubic symphysitis cases?

In discussion section you state: "Pubic symphysis represents less than 1\%", shouldn't it be pubic symphysitis? Still in the discussion section you mention "The diagnosis of septic shock was retained.". What led to this diagnosis? Were other possible conditions considered?

Regarding Figure 1, and to help readers, the zones mentioned should be highlighted in the figure. The same for Figure 3, include a more detailed description in the figure to help the reader to follow the concepts.

"leukocytosis at 10000 and CRP at 30", please indicate the units. 
The discussion could be more focused on the patient, on what could have been done to avoid such an aggravated condition and suggestions for other patients to prevent this complication.

Is the background of the case's history and progression described in sufficient detail? Partly

Are enough details provided of any physical examination and diagnostic tests, treatment given and outcomes?

Yes

Is sufficient discussion included of the importance of the findings and their relevance to future understanding of disease processes, diagnosis or treatment?

Partly

Is the case presented with sufficient detail to be useful for other practitioners? Partly

Competing Interests: No competing interests were disclosed.

Reviewer Expertise: Biomedical engineering, modelling childbirth, finite element analysis

I confirm that I have read this submission and believe that I have an appropriate level of expertise to confirm that it is of an acceptable scientific standard, however I have significant reservations, as outlined above.

Reviewer Report 01 June 2021

https://doi.org/10.5256/f1000research.55480.r85104

(c) 2021 Maselli F. This is an open access peer review report distributed under the terms of the Creative Commons Attribution License, which permits unrestricted use, distribution, and reproduction in any medium, provided the original work is properly cited.

\section{Filippo Maselli}

Department of Neurosciences, Rehabilitation, Ophthalmology, Genetic and Maternal Infantile Sciences (DINOGMI), University of Genoa, Genoa, Italy

I realize that authors have many journals to consider when they want to publish their work, so I appreciate their interest in F1000Research; I am very sorry not to be able to write in a more positive way. It is evident that the authors have put a great deal of effort into this project and I want to praise their efforts, but unfortunately, the actual contribution from their paper to orthopaedic surgery or physical therapy practice' literature is not clear or strong. The manuscript as currently written suggests that it might be suitable for sharing information about this case, but the case report they reported is not representative to state with certainty the conclusions. I am very happy to say that I can review this paper after major revision. It may be that the authors 
would like to consider resubmitting it, in which case I hope that the comments from my review may help them to revise it before resubmitting it. These comments are given below.

For a case report, a lot of information about the case is missing; there is no information which could be an aid in the clinical practice of health professionals who may encounter similar cases. More in depth, the background and clinical reasoning on this patient's clinical presentation is very poor.

The case presentation section is missing more data about patient: history of smoking, sport activity, work activity, etc.

Neither other differential diagnosis hypothesis was supposed, why?

Figures of diagnostic bioimages are missing details and I suggest to add arrows in the figures for marking the clinical findings; they would have helped to better understand the clinical condition and treatment.

What are the real differences compared to similar cases already present in the literature? What really is the patient's clinical condition, Pubic Symphysitis, caused by? Was an underlying medical condition investigated that could support Pubic Symphysitis?

I suggest to add to the references' list, to aid sustaining the background and clinical reasoning in the case presentation section, the following:

1. Finucane et al. $\left(2020^{1}\right)$.

2. Galliker et al. $\left(2020^{2}\right)$.

3. Maselli et al. $\left(2020^{3}\right)$.

I am very sorry not to be able to write in a more positive way but I should like to thank you for give me an opportunity to consider this interesting work for indexing.

\section{References}

1. Finucane LM, Downie A, Mercer C, Greenhalgh SM, et al.: International Framework for Red Flags for Potential Serious Spinal Pathologies.J Orthop Sports Phys Ther. 50 (7): 350-372 PubMed Abstract I Publisher Full Text

2. Galliker G, Scherer DE, Trippolini MA, Rasmussen-Barr E, et al.: Low Back Pain in the Emergency Department: Prevalence of Serious Spinal Pathologies and Diagnostic Accuracy of Red Flags.Am J Med. 133 (1): 60-72.e14 PubMed Abstract | Publisher Full Text

3. Maselli F, Palladino M, Barbari V, Storari L, et al.: The diagnostic value of Red Flags in thoracolumbar pain: a systematic review.Disabil Rehabil. 2020.1-17 PubMed Abstract | Publisher Full Text

Is the background of the case's history and progression described in sufficient detail? Partly

\section{Are enough details provided of any physical examination and diagnostic tests, treatment} given and outcomes? 
Yes

Is sufficient discussion included of the importance of the findings and their relevance to future understanding of disease processes, diagnosis or treatment?

Partly

Is the case presented with sufficient detail to be useful for other practitioners? Partly

Competing Interests: No competing interests were disclosed.

Reviewer Expertise: muscoloskeletal disorders; differential diagnosis; screening for referral; low back pain; sport physical therapy; spinal manipulation; running related injuries

I confirm that I have read this submission and believe that I have an appropriate level of expertise to confirm that it is of an acceptable scientific standard, however I have significant reservations, as outlined above.

The benefits of publishing with F1000Research:

- Your article is published within days, with no editorial bias

- You can publish traditional articles, null/negative results, case reports, data notes and more

- The peer review process is transparent and collaborative

- Your article is indexed in PubMed after passing peer review

- Dedicated customer support at every stage

For pre-submission enquiries, contact research@f1000.com

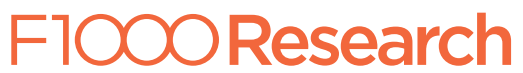

